\title{
A história do Congresso Médico Universitário da FMUSP - COMU
}

\section{The history of "Congresso Médico Universitário da FMUSP - COMU"}

\author{
Alan Saito Ramalho1, Luciana Marques de Vasconcelos², \\ Tarcila Marinho Cippiani²
}

\begin{abstract}
Ramalho AS, Vasconcelos LM de, Cippiani TM. A história do Congresso Médico Universitário da FMUSP - COMU. Rev Med (São Paulo). 2008 jul.-set.;87(3):201-4.

RESUMO: Em 2008, o Congresso Médico Universitário da FMUSP - COMU - chega à sua vigésima sétima edição. O COMU é composto de cursos, palestras, mesas redondas, workshops, jantares e apresentação de trabalhos científicos de acadêmicos que visam contribuir para a formação profissional dos estudantes de medicina, incentivar a pesquisa científica e promover a integração cultural dos participantes. Realizado anualmente desde 1982, o COMU mantém seu sucesso e cresce cada vez mais em infra-estrutura. Para entender o sucesso do COMU, é essencial conhecer sua história e lembrar como e o COMU surgiu.
\end{abstract}

DESCRITORES: Congressos. Educação médica/tendências. Estudantes de medicina.

m 2008, o Congresso Médico Universitário da FMUSP - COMU - chega à sua vigésima sétima edição. Atualmente o COMU reúne mais de 1.200 congressistas, em sua maioria estudantes de medicina, que vem de mais de 30 instituições de ensino médico diferentes.

\section{O que é o COMU?}

O COMU é composto de cursos, palestras, mesas redondas, workshops, jantares e apresentação de trabalhos científicos de acadêmicos que visam contribuir para a formação profissional dos estudantes de medicina, incentivar a pesquisa científica e promo- ver a integração cultural dos participantes.

Durante o COMU, os melhores trabalhos científicos nas áreas básica, clínica, cirúrgica, relato de casos, educação médica e preventiva são coroados com o Prêmio Oswaldo Cruz (POC). Além disso, há o Prêmio Monografias e o Prêmio Painéis.

Realizado anualmente desde 1982, o COMU mantém seu sucesso e cresce cada vez mais em infra-estrutura. Durante 27 anos, o COMU mantémse jovem em sua fórmula, apesar das inúmeras e profundas mudanças que ocorreram ao longo desse período, seja no âmbito do ensino médico ou da prática médica.

Para entender o sucesso do COMU, é

\footnotetext{
1. Acadêmico do $3^{\circ}$ ano do curso de Graduação em Medicina da Faculdade de Medicina da Universidade de São Paulo.

2. Acadêmica do $2^{\circ}$ ano do curso de Graduação em Medicina da Faculdade de Medicina da Universidade de São Paulo.
} 
essencial conhecer sua história e lembrar como o COMU surgiu.

1ํ Congresso de Estudantes de Medicina - 1940 e a Semana Brasileira de Debates Científicos

O Departamento Científico (DC) do Centro Acadêmico Oswaldo Cruz foi fundado por Eduardo Etzel, Paulo de Almeida Toledo e Sebastião Hermeto Júnior em 02 de Março de 1931. Desde essa época é função do Departamento Científico promover atividades que contribuam para a formação médica dos alunos da FMUSP e atividades de extensão universitária, além de incentivar a produção científica do estudante de Medicina e editar a Revista de Medicina'.

Diante disso, em 1940, o então Presidente do Departamento Científico, Carlos da Silva Lacaz, futuramente Catedrático e Diretor da FMUSP, organizou o I Congresso dos Estudantes de Medicina, que foi continuou a ser realizado em outros anos e foi a semente do Congresso Médico Universitário da FMUSP - COMU ${ }^{2}$.

Alguns anos mais tarde, a partir da bem sucedida experiência do Departamento Científico com o Congresso Brasileiro dos Estudantes de Medicina, surge a Semana Brasileira de Debates Científicos, S.B.D.C., que se iniciou em Niterói, em 1947, com a finalidade de congregar acadêmicos de medicina de todo o Brasil para apresentação de trabalhos científicos. Tais trabalhos eram discutidos por professores convidados da escola local organizadora do evento. Esse evento científico acadêmico continuou sendo realizado todos os anos, respectivamente, em Porto Alegre, Distrito Federal, Salvador, Recife e Belo Horizonte, até 1952. A VII Semana realizou-se em Curitiba em 1953. Nela houve a presença maciça dos alunos da Faculdade de Medicina da USP para apresentação de trabalhos, sendo que alguns dos alunos da FMUSP que dela participaram tornaram-se grandes expoentes da ciência, como Norma Woller, uma das maiores expressões em Leucemia Infantil no mundo, trabalhando no Memorial Hospital de Nova York, e Hildebrando Pereira da Silva, grande especialista em doenças tropicais, chegando ao Instituto Pasteur de Paris ${ }^{3}$.

A VIII Semana Brasileira de Debates Científicos realizou-se em São Paulo na Faculdade de Medicina da USP, de 1 a 8 de agosto de 1954, sob os auspícios do Departamento Científico do Centro Acadêmico Oswaldo Cruz (FMUSP) e do Centro Acadêmico Pereira Barreto (EPM). Nela compareceu mais de uma centena de estudantes de todo o Brasil. Dos 60 acadêmicos de São Paulo e 54 de outros estados, foram inscritos 84 trabalhos científicos, apresentados em três sessões diárias, durante 6 dias $^{3}$.
O jornal "O Bisturi", em sua edição de no 70 , de Setembro de 1954, escreve: "podemos afirmar que nos seus 8 anos de existência ininterrupta, a Semana conseguiu mais que aquela finalidade estatutária, pois se evidenciou como verdadeira escola de adestramento na apresentação e discussão de trabalhos científicos, além de afirmar a capacidade realizadora da mocidade e de constituir em autêntica festa de confraternização universitária"”.

No ano seguinte, a Semana Brasileira de Debates Científicos foi realizada em Salvador, voltando posteriormente para São Paulo (Ribeirão Preto), em $1956^{3}$.

1ㄹ Inter-Med - a ciência e o esporte juntos: uma iniciativa do DC e da AAAOC

Além do Congresso Brasileiro dos Estudantes de Medicina e da Semana Brasileira de Debates Científicos, outro evento ajudou a lançar as bases do que viria a ser o $\mathrm{COMU}^{3}$.

Em abril de 1955, em plena Semana Santa realiza-se em Belo Horizonte a Primeira Inter-Med. $O$ objetivo era congregar acadêmicos de medicina de todo o Brasil para debater trabalhos científicos ao mesmo tempo em que se realizavam competições esportivas. A comitiva da Faculdade de Medicina da USP viajou de trem ${ }^{3}$.

Em Belo Horizonte, os alunos ficaram hospedados num galpão de um grupo escolar. De acordo com Henrique Walter Pinotti, que na ocasião era aluno do $6^{\circ}$ ano, era impossível dormir, tamanha a algazarra dos moços liberados. Numa sessão plenária o então Governador do Estado, o médico Dr. Juscelino Kubitschek de Oliveira, falou aos participantes da Primeira Inter-Med, dissertando longamente sobre seu programa de governo, "binômio energia e transporte". Como é sabido, ele estava em plena campanha preparatória para Presidência, que de fato conquistou ${ }^{3}$.

Dácio Montans, que foi membro da delegação da FMUSP na Primeira Inter-Med assim relatou em "O Bisturi", edição de Agosto de 1955: "Antes de mostrar aos colegas o que de concreto foi realizado neste setor da Inter-Med Nacional (primeira), sentimo-nos obrigados a esclarecer a participação que teve o Departamento Científico no preparo de nossa delegação científica, que soube tão bem elevar o nome de nossa Faculdade no Congresso de Belo Horizonte"3.

Essa primeira Inter-Med decorreu em ambiente de cavalheirismo e seriedade nas sessões científicas e esportivas e consolidou entre os alunos da FMUSP a importância da congregação científica dos estudantes de medicina. Tal espírito, mantido vivo 
Ramalho AS et al. A história do Congresso Médico Universitário da FMUSP - COMU.

pelo Departamento Científico do CAOC, alguns anos mais tarde, levou à realização do I Congresso Médico Universitário da FMUSP - COMU, em $1982^{3}$.

\section{Congresso Médico Universitário da FMUSP - 1982}

O Congresso Médico Universitário da FMUSP surgiu da vontade de alguns alunos de montar um congresso dentro da própria casa, como já acontecia em algumas outras faculdades de medicina do país.

Em 1980 começou-se a pensar em como montar o primeiro congresso e levou todo o ano de 1981 e parte de 1982 para ser concretizado. As dificuldades iniciais foram principalmente onde seriam realizadas as aulas e como as despesas geradas pelo congresso seriam pagas. Para isso, a primeira equipe de organizadores contou com o apoio do então diretor da faculdade, Prof. Dr. Mário Ramos de Oliveira, e com a presença de laboratórios que patrocinaram a divulgação e brindes.

O I COMU aconteceu entre os dias 31 de maio e 5 de junho de 1982. Contou com 6 opções de cursos, palestras, uma mesa redonda e apresentação de trabalhos científicos, incluindo o Prêmio Oswaldo Cruz.

O primeiro presidente do COMU foi Paulo Manuel Pego Fernandes, que na época cursava o 6ํㅡㅁ ano da graduação, hoje Professor Associado do Departamento de Cardiopneumologia da FMUSP. O primeiro presidente de honra foi o diretor da faculdade, Prof. Dr. Mário Ramos de Oliveira.

\section{O COMU ao longo dos anos}

Desde o seu surgimento em 1982, o COMU conta com um grande público. Logo no primeiro congresso foram mais de 500 participantes de todo o estado de São Paulo e outros, como Minas Gerais, Rio de Janeiro, Paraná, Paraíba e Rio Grande do Sul. A última edição, em 2007, contou com cerca de 1200 congressistas, sendo o maior COMU já realizado.

Apesar de ser um público majoritário de estudantes de medicina, o congresso sempre contou com a participação de acadêmicos de outros cursos da área da saúde e biológicas como enfermagem, fisioterapia, nutrição, psicologia, biomedicina, farmácia bioquímica e ciências biológicas.

A estrutura do congresso mudou ao longo do tempo: logo no início existiam poucos cursos organizados em módulos, mas contava com um grande número de palestras e mesas redondas sobre os mais diversos temas, discussão de casos e atividades culturais como amostra de filmes, documentários, apresentações musicais e de teatro. Os workshops, que hoje são um dos grandes atrativos deste congresso, surgiram no XIV COMU (1995), mas só se tornaram constantes a partir do XXIV COMU (2005).

O Prêmio Oswaldo Cruz esteve presente desde o I COMU, sendo por muito tempo o único prêmio a ser realizado. O Prêmio Monografias surgiu apenas no XIV COMU (1995) e o Prêmio Painéis no XVI COMU (1997). Antes de surgirem esses dois prêmios, havia apresentações de trabalhos não concorrentes ao POC que chegaram a ser, em algumas edições, em maior número do que as que concorriam ao POC.

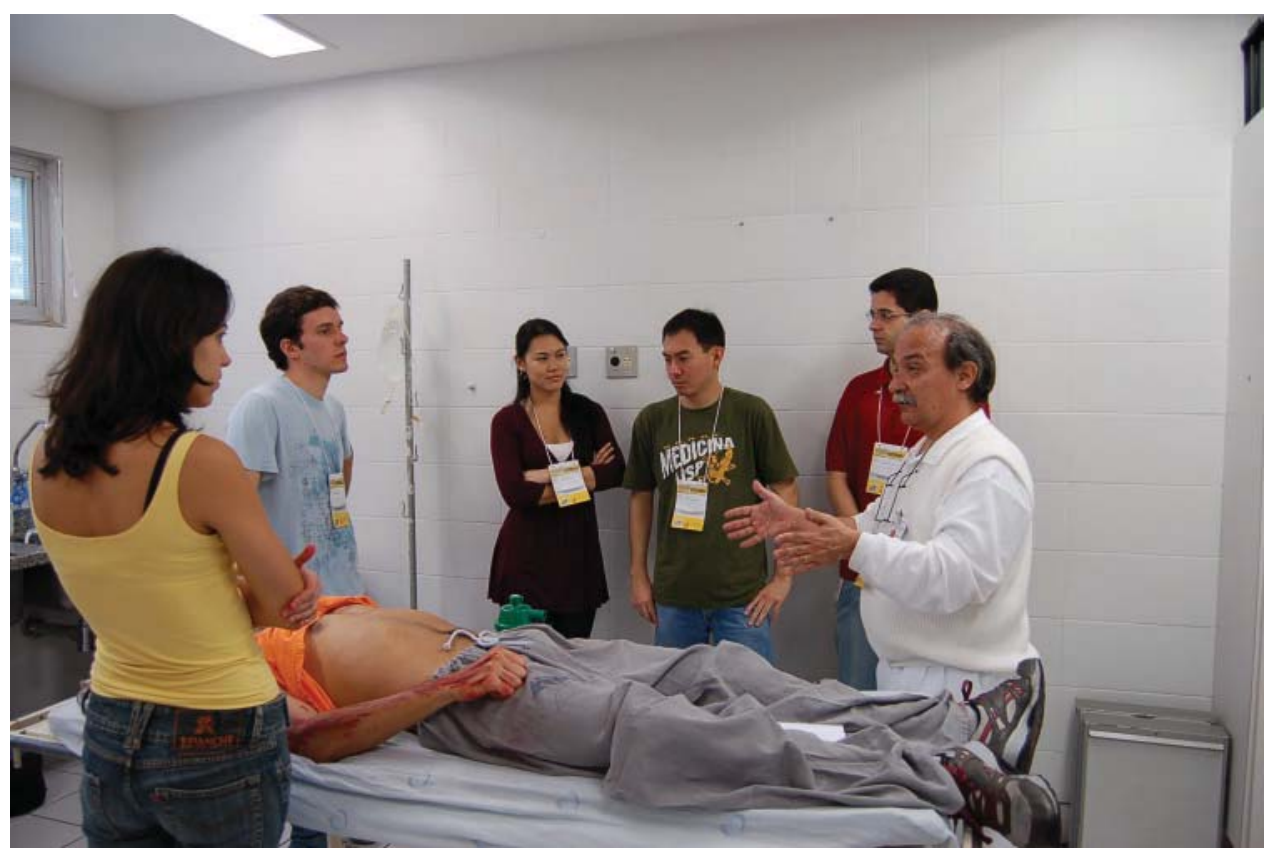

FOTO 1. Workshop de ATLS com o Dr. Mário Quintas, no XXVII COMU - 2008 


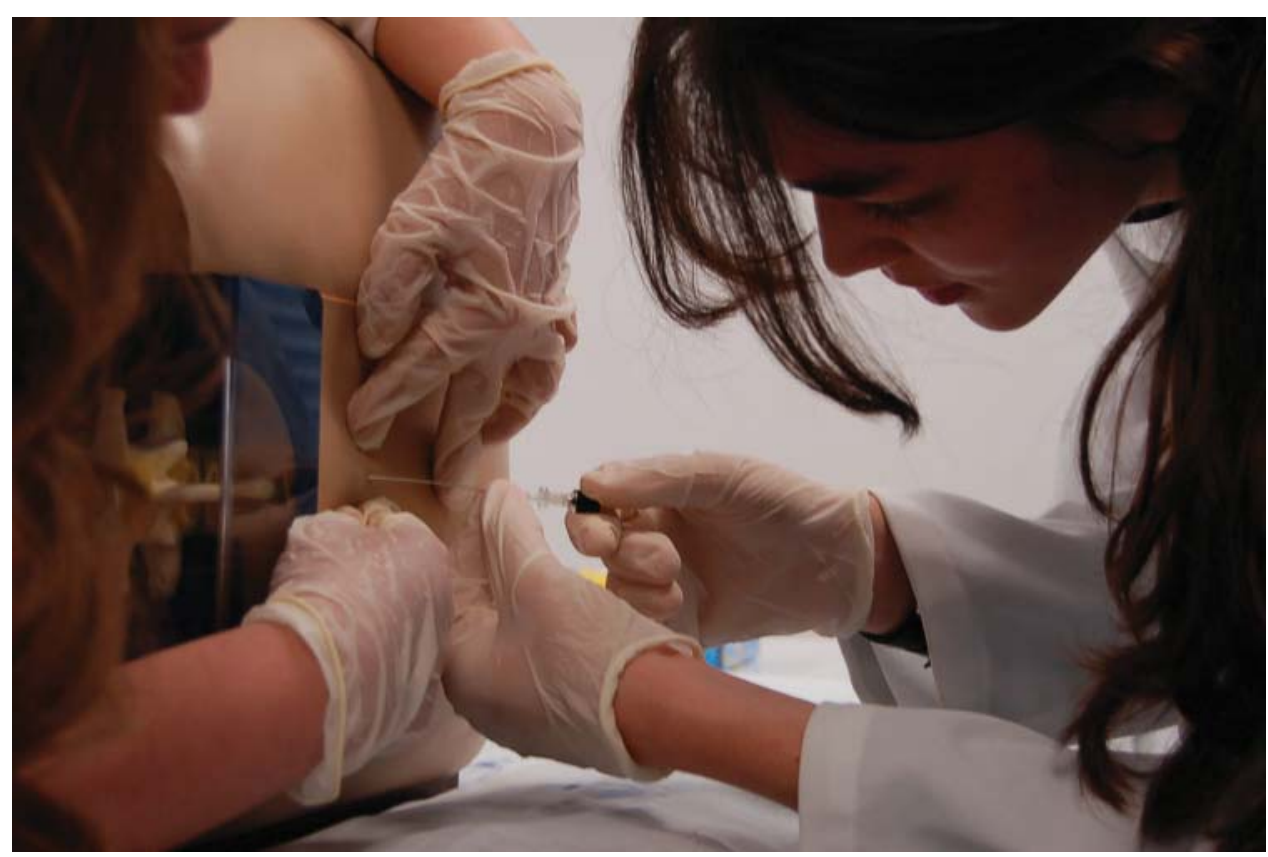

FOTO 2. Workshop de Emergências Clínicas, XXVII COMU - 2008

Ramalho AS, Vasconcelos LM de, Cippiani TM. The history of "Congresso Médico Universitário da FMUSP - COMU”. Rev Med (São Paulo). 2008 jul.-set.;87(3):201-4.

ABSTRACT: In 2008, the Congresso Médico Universitário da FMUSP - COMU - comes to its 27th edition. The COMU consists of courses, seminars, workshops, dinners and presentation of academics scientific works which purpose is to contribute to the medical formation, stimulate scientific research e promote cultural integration. Among partakers. It has been taken place annually since 1982, maintaining its success and improving its infrastructure. To understand COMU's success is essential to know its history and remember how the first COMU was created.

KEY WORDS: Congress. Education, medical. Students, medical.

\section{REFERÊNCIAS}

1. Lacaz C da S. Faculdade de Medicina: reminiscência, tradição, memória de minha escola. São Paulo: Edição do Autor; 1985.

2. Marinho MGSMC. Trajetória da Faculdade de Medicina da Universidade de São Paulo: aspectos históricos da "Casa de Arnaldo". São Paulo: FMUSP; 2006.
3. Pinotti HW, Gouvêa FP, Ferreira Filho AA, Bacalá L. Reminiscência da Casa de Arnaldo: trajetória de 83 jovens responsáveis, coesos e alegres pela Faculdade de Medicina da Universidade de São Paulo de 1950 a 1955. São Paulo: Edições O.L.M.; 2005. 